\title{
Non-invasive ventilation in hypercapnic COPD exacerbation: Predictors of mortality
}

\author{
August Supervía ${ }^{1,2,3 *}$, Oriol Pallàs ${ }^{1,2}$, María Canas ${ }^{1}$, Francisco del Baño ${ }^{1}$, Isabel Cirera ${ }^{1,3}$, María Luisa Iglesias ${ }^{3,4}$ and Juan Pedro-Botet $^{2,3,5}$ \\ ${ }^{1}$ Emergency Department, Hospital del Mar, Barcelona, Spain \\ ${ }^{2}$ IMIM (Institut Hospital del Mar d'Investigacions Mèdiques), Barcelona, Spain \\ ${ }^{3}$ Universitat Autònoma de Barcelona, Spain \\ ${ }^{4}$ Emergency Department, Corporació Sanitaria Parc Taulí, Sabadell, Barcelona, Spain \\ ${ }^{5}$ Endocrinology and Nutrition Department. Hospital del Mar, Barcelona, Spain
}

\begin{abstract}
Background: Long-term survival after non-invasive ventilation (NIV) in patients with chronic obstructive pulmonary disease (COPD) and acute hypercapnic respiratory failure is a significant outcome.

Objective: To determine mortality at 1,2 and 5 years after NIV and analyze the possible factors related to mortality in patients with COPD and hypercapnic respiratory failure.
\end{abstract}

Methods: Retrospective study of patients with COPD requiring NIV in the emergency department of a general hospital between 1997 and 2002 . Mortality to discharge at 1,2 and 5 years and related factors were determined.

Results: NIV failed in 18 (8.7\%) of 207 included patients. Hospital mortality was $8.2 \%$, and 1-, 2- and 5-year mortality after discharge was $24.6 \%$, 31\% and 47.3\%, respectively. The best mortality predictor model at five years was FEV1, SAPS II score and home oxygen therapy, with an area under the curve of 0.83 (95\% CI 0.75-0.91).

Conclusions: Mortality at five years in patients with COPD exacerbations undergoing NIV was less than 50\% and predictive factors were SAPS II, home oxygen therapy and FEV [1].

\section{Introduction}

Exacerbation of chronic obstructive pulmonary disease (COPD) accounts for up to $1.2 \%$ of cases treated in the emergency department, with $50 \%$ requiring admission [1]. Non-invasive ventilation (NIV), the treatment of choice for exacerbations with acute hypercapnic respiratory failure with acidosis, $[2,3]$ has been used in clinical practice since the end of the last century,[4-6] and reduces the need for orotracheal intubation, costs and length of stay,[7] and increases survival in these patients. [4,6-9] Nevertheless, despite its proven efficacy,[4-6,10] few studies have evaluated long-term survival after NIV therapy in acute respiratory failure in COPD. We hypothesized that several factors may influence survival after NIV treatment in COPD exacerbations with hypercapnic respiratory failure with acidosis. The aim of the present study was to determine mortality at 1,2 and 5 years after NIV in these patients and analyze the possible factors related to mortality in patients with COPD and hypercapnic respiratory failure.

\section{Methods}

A retrospective study of all COPD patients, seen for hypercapnic respiratory failure in the emergency department of a university hospital from 1997 to 2002 was conducted. The patients included were previously recruited in a longitudinal study [11]. All patients were treated with NIV in the emergency department and reviewed at 1 , 2 and 5 years. Inclusion and exclusion criteria were described in the previous longitudinal study [11]. Briefly, NIV was indicated based on blood gas criteria $\left(\mathrm{pH}<7.33, \mathrm{PaCO}_{2}>55 \mathrm{~mm} \mathrm{Hg}\right.$ ) after the lack of clinical and gasometric improvement with conventional medical treatment had been verified. This study was approved by the teaching hospital's institutional review board.

Clinical data collected included age and gender, forced expiratory volume at 1 second $\left(\mathrm{FEV}_{1}\right)$ analyzed in the 6 months prior to treatment, vital signs (temperature, blood pressure, heart and respiratory rates), use of home oxygen, cause of exacerbation and arterial blood gases and severity evaluated by the simplified acute physiology score (SAPS II). Arterial blood gases were measured at admission, at the start of NIV and at 6 and 24 hours and at the end of NIV. An encephalopathy scale was applied at the same time [6]. Follow-up was made through clinical history and telephonic contact. The number of re-admissions was registered in the following two years and mortality at 1,2 and 5 years.

NIV was performed with double-pressure ST and S/T-D 30 ventilators from Respironics Inc. Nasobucal face mask Spectrum

Correspondence to: August Supervía, Emergency Department, Hospital del Mar. Passeig Marítim, 25-29. 08003 Barcelona, Spain, Tel: +34 932483017, Fax: +34 932483016; E-mail: 88483@parcdesalutmar.cat.

Key words: COPD; non-invasive ventilation; respiratory failure

Received: September 28, 2017; Accepted: October 23, 2017; Published: October 25,2017 
with fastening system of Respironics and nasal and frontal protection patches (Algoplaque) were used. Ventilation was started at spontaneous/temporized mode, with prefixed parameters (IPAP: 8-12 $\mathrm{cm}$ of $\mathrm{H}_{2} \mathrm{O}$ and EPAP: $4 \mathrm{~cm}$ of $\mathrm{H}_{2} \mathrm{O}$ ). These parameters were adjusted until tidal volume $>400 \mathrm{ml}$ was achieved. Oxygen flow necessary to attain a $\mathrm{SO}_{2} \geq 90 \%$ was used. NIV failure was defined when the patient did not tolerate it, worsened and orotracheal intubation was added, or when improvement was not demonstrated by gasometric criteria (persistence of acidosis at 12 hours after the start of NIV) or clinical criteria (appearance of signs of muscular fatigue or worsening of consciousness level).

Statistical analysis was made with the SPSS program, version 15.0 for Windows. Student's t-test was used for comparison of averages, $\chi^{2}$ test for the analysis of categorical variables, and the Mann-Whitney $\mathrm{U}$ test for variables that did not follow a normal distribution. To identify factors associated with mortality, a univariate regression analysis was made for each of the independent variables. Multivariate logistic regression analysis was then performed to identify independent associated factors with mortality. Finally, a ROC curve was constructed for diagnostic efficiency.

\section{Results}

Two hundred and seven patients were included over the study period. One hundred and fifty-five (74.9\%) were male, and mean age was $68 \pm 11$ years. Fifty patients $(24.4 \%)$ were treated with home oxygen, $65(32.2 \%)$ had previously been treated with NIV for acute respiratory failure and $24(11.9 \%)$ had previously required mechanical ventilation. The severity index SAPS II was $12.6 \pm 4$. Baseline characteristics are show in Table 1.

Ventilation duration was $35 \pm 21$ hours; time of the start of NIV from arrival at the emergency department was $7.6 \pm 8.5$ hours, and the length of stay was $15 \pm 9$ days. NIV was effective in 89 (91\%) patients and failed in 18 (9\%), 13 (72\%) of whom required orotracheal intubation and mechanical ventilation. In the remaining 5 patients, owing to severe baseline conditions, no other measures were applied.

During the review period, fifteen patients were lost in the first year, 26 in the second year, and 50 at the end of the fifth year.

Hospital mortality was $8.2 \%$. Two of the 13 (15.4\%) patients who received mechanical ventilation died. Mortality at 1,2 and 5 years after discharge was $24.6 \%, 31 \%$ and $47.3 \%$, respectively. Age, $\mathrm{FEV}_{1}$, home oxygen and SAPS II score were associated with mortality in all periods (Table 2). On the other hand, the requirement for intubation and readmissions after NIV was not associated with mortality in any of the analyzed periods. Of the remaining parameters, only $\mathrm{pH}$ value at the start of NIV was associated with mortality at one year $(7.26 \pm 0.05$ vs $7.28 \pm 0.03 ; \mathrm{p}=0.03$ ).

The results of multivariate analysis at 2 and 5 years are shown in Table 3 . The best predictive model of mortality at 2 years included the SAPS II score and home oxygen treatment [area under the curve [(AUC) 0.75 ; 95\% CI: 0.65-0.84], while the best model that predicted mortality at 5 years involved the $\mathrm{FEV}_{1}$ plus the other two (AUC 0.83; 95\% CI: $0.75-0.91)$. Inclusion of the intubation parameter in the model did not modify the results.

\section{Discussion}

The results of the present study are in line with previous clinical evidences of NIV in the treatment of severe exacerbation of COPD and confirm that its application in the emergency department of a general
Table 1. Baseline characteristics of patients at admission, gasometric parameters and encephalopathy presence at admission, start and end of NIV.

\begin{tabular}{|c|c|c|c|}
\hline & \multicolumn{3}{|l|}{ Admission } \\
\hline Age & \multicolumn{3}{|l|}{$68(11)$} \\
\hline $\operatorname{Sex}(\%)$ & \multicolumn{3}{|c|}{$74.9 \mathrm{M} / 25.1 \mathrm{~F}$} \\
\hline Home oxygen (\%) & \multicolumn{3}{|c|}{$65(32.2)$} \\
\hline $\mathrm{FEV}_{1}$ (\% ref.) & \multicolumn{3}{|l|}{$32.4(11)$} \\
\hline Previous treatment with NIV (\%) & \multicolumn{3}{|l|}{$24(11.9)$} \\
\hline SAPS II & \multicolumn{3}{|l|}{$12.6(4)$} \\
\hline $\begin{array}{l}\text { Exacerbation causes* } \\
\text { Bronchial infection } \\
\text { Pneumonia } \\
\text { Heart failure } \\
\text { Treatment withdrawal } \\
\text { Benzodiazepine intake } \\
\text { No identifiable cause }\end{array}$ & $\begin{array}{l}62.3 \\
18.4 \\
4.8 \\
1.4 \\
1.0 \\
15.0\end{array}$ & & \\
\hline & Admission & Start NIV & End NIV \\
\hline pH & $7.3(0.0)$ & $7.27(0.0)$ & $7.37(0.0)$ \\
\hline $\mathrm{pO}_{2}(\mathrm{~mm} \mathrm{Hg})$ & $52.0(15)$ & $62.2(17)$ & 70.7 (14) \\
\hline $\mathrm{pCO}_{2}(\mathrm{~mm} \mathrm{Hg})$ & $68.5(12)$ & $77.9(13)$ & $59.9(10)$ \\
\hline Respiratory rate & $33(7)$ & $31.5(5)$ & $23(3)$ \\
\hline Presence of encephalopathy (\%) & $53.3 \%$ & $64.6 \%$ & $15.9 \%$ \\
\hline
\end{tabular}

Values expressed as percentage by sex, home oxygen, $\mathrm{FEV}_{1}$, previous treatment with NIV, causes of exacerbation and presence of encephalopathy. Other values are expressed as mean (standard deviation).

$\mathrm{FEV}_{1}$ : forced expiratory volume in one second; NIV: noninvasive ventilation. This treatment only refers to patients with acute exacerbation. No patients included in the study received treatment with home NIV; SAPS, simplified acute physiology score; presence of encephalopathy: any degree of encephalopathy.

*More than one exacerbation cause is possible. For this reason, the total percentage exceeds $100 \%$.

hospital is feasible and safe [8-10]. A Cochrane review evaluated patient mortality in 10 studies with NIV for COPD exacerbation. There was a significant benefit, with a number needed to treat of just 10 to improve the mortality rate [12]. In this respect, the present study revealed a low rate of immediate mortality in these patients despite the complexity level of patients with COPD, given the high SAPS II score, the use of home oxygen, as well as history of previous NIV and mechanical ventilation. It should be noted that NIV failure did not influence patient mortality, which concurs with a multicenter study conducted in 31 Spanish intensive care units (ICU) [13].

Mortality rates at 2 and 5 years (31\% and 47.3\%) were lower compared with those of other studies where mortality at 5 years postNIV was around 74\% [14]. A possible explanation for these different mortality rates could lie in the study design, particularly in the patient selection criteria. For example, other studies recruited all patients treated with NIV regardless of the clinical cause, while in our study only COPD exacerbations were included. Other possible explanations could be the inclusion of few patients in whom NIV was offered for the second time, and that a small percentage of COPD exacerbations was due to pneumonia and heart failure.

Age, $\mathrm{FEV}_{1}$, home oxygen and SAPS II score were associated with mortality in all analyzed periods; however, age lost significance in the logistic regression analysis. Chung et al with a similar study design reported that age, body mass index and home oxygen were the mortality associated factors at 5 years [14].

Home oxygen treatment was associated with mortality in both studies, but the present study highlights the importance of SAPS score before starting NIV.

The lack of an association between mortality and the encephalopathy scale and blood gas values deserves to be remarked; however, this finding concurs in part with other studies that evaluated short- and 
Table 2. Differences between deceased and surviving patients in the studied periods.

\begin{tabular}{|c|c|c|c|c|c|}
\hline & & Age & $\mathrm{FEV}_{1}$ & SAPS & $\mathrm{O}_{2}$ \\
\hline \multirow[t]{2}{*}{$1^{\text {st }}$ year } & $\begin{array}{c}\text { Deceased }(n=52) \\
\text { Alive }(n=140) \\
\text { Lost }(n=15)\end{array}$ & $\begin{array}{c}74.7(9.5) \\
65.7(10.1)\end{array}$ & $\begin{array}{c}28.1(8.7) \\
33.6(10.9)\end{array}$ & $\begin{array}{l}15.3(3.2) \\
11.8(3.8)\end{array}$ & $\begin{array}{l}41.9 \% \\
58.1 \%\end{array}$ \\
\hline & $\mathbf{P}$ & $<0.001$ & 0.01 & $<0.001$ & 0.008 \\
\hline \multirow[t]{2}{*}{$2^{\text {nd }}$ year } & $\begin{array}{c}\text { Deceased }(n=75) \\
\text { Alive }(n=106) \\
\text { Lost }(n=26)\end{array}$ & $\begin{array}{c}72.6(9.6) \\
64.8(10.3)\end{array}$ & $\begin{array}{c}28.8(7.9) \\
34.4(11.6)\end{array}$ & $\begin{array}{l}14.5(3.5) \\
11.6(3.9)\end{array}$ & $\begin{array}{l}60 \% \\
40 \%\end{array}$ \\
\hline & $\mathbf{P}$ & $<0.001$ & 0.001 & $<0.001$ & 0.003 \\
\hline \multirow[t]{2}{*}{$5^{\text {th }}$ year } & $\begin{array}{c}\text { Deceased }(n=97) \\
\text { Alive }(n=60) \\
\text { Lost }(n=50)\end{array}$ & $\begin{array}{l}71.2(10.3) \\
63.8(10.2)\end{array}$ & $\begin{array}{c}29.3(8.7) \\
37.25(11.7)\end{array}$ & $\begin{array}{c}14(3.8) \\
11.3(3.9)\end{array}$ & $\begin{array}{l}84.2 \% \\
15.8 \%\end{array}$ \\
\hline & $\mathbf{P}$ & $<0.001$ & $<0.001$ & $<0.001$ & 0.001 \\
\hline
\end{tabular}

NS: non-significant.

SAPS, simplified acute physiology score; $\mathrm{O}_{2}$, oxygen, $\mathrm{FEV}_{1}$, forced expiratory volume reference value).

SAPS, simplified acute physiology score; $\mathrm{O}_{2}$, oxygen, $\mathrm{FEV}_{1}$, forced expiratory volume.

Table 3. Independent factors associated with mortality at 2 and 5 years of follow-up.

\begin{tabular}{|c|c|c|c|c|}
\hline Follow-up & Factor & OR & $\mathbf{9 5 \%}$ CI & P \\
\hline \multirow{2}{*}{$2^{\text {nd }}$ year } & SAPS II & 1.28 & $1.16-1.41$ & $\mathrm{p}<0.001$ \\
\cline { 2 - 5 } & $\mathrm{Home} \mathrm{O}_{2}$ & 5.17 & $2.25-11.87$ & $\mathrm{p}<0.001$ \\
\hline \multirow{3}{*}{$\mathbf{5}^{\text {th }}$ year } & SAPS II & 1.12 & $1.00-1.24$ & $\mathrm{p}=0.044$ \\
\cline { 2 - 5 } & $\mathrm{Home} \mathrm{O}_{2}$ & 4.50 & $1.50-13.50$ & $\mathrm{p}=0.007$ \\
\cline { 2 - 5 } & FEV $_{1}$ & 0.94 & $0.89-0.98$ & $\mathrm{p}=0.009$ \\
\hline
\end{tabular}

SAPS, simplified acute physiology score. $\mathrm{O}_{2}$, oxygen; $\mathrm{FEV}_{1}$, forced expiratory volume at 1 second ( $\%$ of reference value).

long-term mortality in patients with COPD exacerbations $[15,16]$.

Limitations of the present study were mainly due to the retrospective nature of the follow-up and to it being performed at a single center. Another limitation could be the definition of NIV failure at 12 hours, since it has not been adapted to the time described in the latest reviews [17]. There is a gap between the criteria used at the time of starting the study and the current clinical guidelines. In addition, the previous longitudinal study was not designed to evaluate mortality. Nevertheless, the inclusion of all patients who needed NIV reflects the daily clinical reality of our environment.

NIV was effective in more than $90 \%$ patients with COPD exacerbations at the emergency department, with a low immediate mortality rate. Mortality at five years in these patients was less than $50 \%$ and predictive factors were SAPS II, home oxygen therapy and $\mathrm{FEV}_{1}$, as a marker of airflow obstruction severity.

\section{Acknowledgment}

We thank Miss Christine O'Hara for review of the English version of the manuscript and Mr. Sergi Mojal for the statistical advice.

\section{References}

1. Otero González I, Blanco Aparicio M, Valiño López P, Verea Hernando H (2002) Características epidemiológicas de las exacerbaciones por EPOC y asma en un hospital general. Arch Bronconeumol 38: 256-262.

2. Nova S, Hill N (2009) Non-invasive ventilation in acute respiratory failure. Lancet 374: $250-259$

3. Miravitlles M, Ferrer M, Pont A, Zalacain R, Alvarez-Sala JL, et al (2004) IMPAC Study Group. Exacerbations impair quality of life in patients with chronic obstructive pulmonary disease. A two-year follow-up study. Thorax 59: 387-395. [Crossref]

4. Diaz O, Iglesia R, Ferrer M, Zavala E, Santos C, et al. (1997) Effects of noninvasive ventilation on pulmonary gas exchange and hemodynamics during acute hypercapnic exacerbations of chronic obstructive pulmonary disease. Am J Respir Crit Care Med 156: 1840-1845. [Crossref]
5. Brochard L, Isabey D, Piquet J, Amaro P, Mancebo J, et al. (1990) Reversal of acute exacerbations of chronic obstructive lung disease by inspiratory assistance with a face mask. N Engl J Med 323: 1523-1530. [Crossref]

6. Meduri GU, Abou-Shala N, Fox RC, Jones CB, Leeper KV, et al. (1991) Noninvasive face mask mechanical ventilation in patients with acute hypercapnic respiratory failure. Chest 100: 445-454. [Crossref]

7. Brochard L, Mancebo J, Wysocki M, Lofaso F, Conti G, et al. (1995) Noninvasive ventilation for acute exacerbations of chronic obstructive pulmonary disease. $N$ Engl $J$ Med 333: 817-822. [Crossref]

8. Keenan SP, Sinuff T, Cook DJ, Hill NS (2003) Which patients with acute exacerbation of chronic obstructive pulmonary disease benefit from noninvasive positive-pressure ventilation? A systematic review of the literature. Ann Intern Med 138: 861-870. [Crossref]

9. Kramer N, Meyer TJ, Meharg J, Cece RD, Hill NS (1995) Randomized, prospective trial of noninvasive positive pressure ventilation in acute respiratory failure. $\mathrm{Am} \mathrm{J}$ Respir Crit Care Med 151: 1799-1806. [Crossref]

10. British Thoracic Society Standards of Care Committee (2002) Non-invasive ventilation in acute respiratory failure. Thorax 57: 192-211.

11. Iglesias ML, Gutiérrez J, Pedro-Botet J, Solsona JF, López MJ, et al. (2001) Effectiveness of noninvasive positive pressure ventilation type BIPAP with face mask in patients with COPD and acute respiratory failure whit hypercapnia (respiratory acidosis), in the Emergency Department. Emergencias 13: 26-30.

12. Ram FS, Picot J, Lightowler J, Wedzicha JA (2004) Non-invasive positive pressure ventilation for treatment of respiratory failure due to exacerbations of chronic obstructive pulmonary disease. Cochrane Database Syst Rev: CD004104. [Crossref]

13. Delgado M, Marcos A, Tizón A, Carrillo A, Santos A, et al. (2012) Impact of noninvasive ventilation failure upon patient prognosis. Subanalysis of a multicenter study. Med Intensiva 36: 604-610.

14. Chung LP, Winship P, Phung S, Lake F, Waterer G (2010) Five-year outcome in COPD patients after their first episode of acute exacerbation treated with non-invasive ventilation. Respirology 15: 1084-1091. [Crossref]

15. Quintana JM, Esteban C, Unzurrunzaga A, Garcia-Gutierrez S, Gonzalez N, et al (2014) Predictive score for mortality in patients with COPD exacerbations attending hospital emergency departments. BMC Medicine 12: 66. [Crossref]

16. Berkius J, Sundh J, Nilholm L, Fredrikson M, Walther SM (2010) Long-term survival according to ventilation mode in acute respiratory failure secondary to chronic obstructive pulmonary disease: a multicenter, inception cohort study. J Crit Care 25: 539.e13-18. [Crossref]

17. Ozyilmaz E, Ugurlu AO, Nava S1 (2014) Timing of noninvasive ventilation failure: causes, risk factors, and potential remedies. BMC Pulm Med 14: 19. [Crossref]

Copyright: (C2017 Supervía A. This is an open-access article distributed under the terms of the Creative Commons Attribution License, which permits unrestricted use, distribution, and reproduction in any medium, provided the original author and source are credited. 